\title{
Nutrigenomics: where are we with genetic and epigenetic markers for disposition and susceptibility?
}

Martin Kussmann, Lutz Krause, and Winfried Siffert

\begin{abstract}
The revelation of the human genome has enabled scientists to assess the disposition and response of an organism to an environmental stimulus; transcriptomics, proteomics, and metabonomics can each generate such holistic views. Nutrigenomic techniques help researchers elucidate individual responses to nutritional interventions holistically and help with the design of personalized diets adapted to individual needs. Human genetics has revealed insights into health and disease susceptibility and can help differentiate responders from nonresponders in dietary interventions, but the predictive power of single-nucleotide polymorphisms in disease susceptibility genes has so far been limited in terms of helping to foresee a health trajectory. Epigenetics encompasses alterations of genetic material that do not affect the DNA nucleotide sequence; these include DNA methylation patterns, chromatin structure, histone codes, and non-coding small RNAs. DNA methylation is modified particularly around the time of birth; therefore, early-life nutrition may affect health outcomes later in life.

(c) 2010 ILSI Europe
\end{abstract}

\section{INTRODUCTION}

Catalyzed by the revelation of the human genome, ${ }^{1,2}$ genomics can now assess the disposition, response, or expression of a living system (cell, organ, and entire organism) to an environmental (e.g., nutritional) stimulus or challenge; transcriptomics, proteomics, and metabonomics can generate such holistic views of biological conditions at the levels of the gene transcript, protein, and metabolite. ${ }^{3}$ Although genetics provides a blueprint (i.e., what may happen), the transcripts provide an action plan (i.e., what appears to happen), the proteins are what make it happen, and the metabolites can tell a story (i.e., what has happened). ${ }^{4}$

Broadly defined, human genetics is the study of the human genome sequence and its interindividual variations; it can reveal insights into health prospects and disease susceptibility ${ }^{5}$ and can differentiate responders from nonresponders in dietary interventions. ${ }^{6}$ Although the latter genetics-based cohort stratification has been shown to be possible and powerful in certain cases, the predictive power of single-nucleotide polymorphisms (SNPs), or combinations of them, found in so-called disease susceptibility genes and revealed as risk loci, has been relatively limited when it comes to foreseeing a health trajectory or disease onset. ${ }^{7,8}$ These SNPs could, so far, only explain a small degree of the phenotypic variability in question. ${ }^{9}$ Apparently, the genomic compensation around these SNPs is important, so the same set of SNPs may matter for one (sub)population but not for another. This might be one of the reasons why replication of risk loci in different populations is still difficult. ${ }^{10}$ These findings contrast somewhat with the blossoming of genetic counseling companies that provide consumers with risk assessment and life-style recommendations based on their individual genetic profile (e.g., their particular set of SNPs in diseaserelated genes). ${ }^{11}$

Affiliations: Martin Kussmann is with the Functional Genomics Group, Nestlé Research Center, Lausanne, Switzerland; Faculty of Science, Aarhus University, Denmark. Lutz Krause is with the Functional Genomics Group, Nestlé Research Center, Lausanne, Switzerland. Winfried Siffert is with the Institute of Pharmacogenetics, University Hospital Essen, Germany.

Correspondence: ILSI Europe a.i.s.b.I., Av. E Mounier 83, box 6, 1200 Brussels, Belgium. E-mail: publications@ilsieurope.be, Phone: +32-2-771-00-14, Fax: +32-2-762-00-44.

Key words: biomarker, brain, cognition, epigenetics, nutrigenetics, nutrigenomics 
Epigenetics is an even newer field of genetic and genomic sciences. It literally means "above genetics" and alludes to alterations of genetic material that do not affect the DNA sequence itself, i.e., DNA methylation patterns, ${ }^{12}$ chromatin structure, ${ }^{13}$ and histone codes, ${ }^{14}$ as well as noncoding small RNAs. ${ }^{15}$ DNA methylation can be exerted at susceptible life phases (especially around birth) and last for a life phase, the entire lifespan, or even several generations. It seems to provide a major format for long-term metabolic imprinting of an organism; thus, early-life nutrition may affect later-life health outcomes. ${ }^{16}$ Like DNA methylation patterns, DNA packaging proteins such as histones and the entire chromatin structure also affect gene expression by rendering only certain parts of the DNA material spatially accessible for transcription. ${ }^{17}$ Small RNAs can bind to complementary transcripts and prevent them from being processed further, thereby altering protein expression. ${ }^{15}$ Overall, epigenetic modifications can exert a long-term effect on gene expression.

This article focuses on the deployment of genetics (with a strong focus on $\mathrm{G}$ proteins) and epigenetics to assess individual disposition for response to (nutritional) intervention. It also alludes to the scientific interfaces among genes, nutrition, and the brain. Knowledge about the binary interfaces of these disciplines has been accumulated, but little is known about the intersection of all three scientific domains (e.g., about how genes affect human brain development and decline or how humans differ in their amenability to nutritional intervention aimed at promoting brain development and preventing neuronal decline and loss of cognitive function).

\section{GENETICS}

\section{Genetics and nutrition}

Nutrigenetics assesses an individual's genetic predisposition to diet. SNPs are point mutations in genes and account for the most common and important interindividual genetic differences at the sequence level known to date. ${ }^{18}$ These SNPs occur in exons and introns (in coding and noncoding DNA regions), and many have important functional consequences. ${ }^{19}$

\section{G proteins}

As one of the few established examples for stratification of cohorts in nutritional intervention studies based on genetic variants in a given class of proteins, the case of $\mathrm{G}$ protein polymorphisms is discussed here. Genetic predispositions with regard to cognitive performance and decline, as well as to possible nutritional interventions, are discussed in the section titled "Genes, nutrition, and the brain."
$\mathrm{G}$ proteins are expressed in all cells of the human body; their main role is to translate signals from the cell surface into a cellular response. ${ }^{20} \mathrm{G}$ proteins are heterotrimers and are composed of $\alpha, \beta$, and $\gamma$ subunits. The family of $G$ proteins comprises $18 \alpha$ subunits, $5 \beta$ subunits, and $12 \gamma$ subunits encoded by different genes, ${ }^{21}$ which enables the formation of highly variable $G$ protein heterotrimers. The $\alpha-, \beta$-, and $\gamma$-subunit composition of $G$ proteins determines their receptor and effector specificity. ${ }^{22}$ Given the pivotal role of $\mathrm{G}$ proteins in virtually all intracellular signal transduction processes, it is assumed that mutations altering the expression or structure of these proteins causes or contributes to health disorders. ${ }^{6}$ Metabolically relevant SNPs in G proteins have been characterized. ${ }^{6,23-29}$ In Caucasians, the genotype distribution of the C825T polymorphism in the G-protein $\beta 3$ (GNB3) subunit gene is $10 \% \mathrm{TT}, 45 \% \mathrm{TC}$, and $45 \% \mathrm{CC}$, with an average frequency of the $\mathrm{T}$ allele near $30 \%$. Some ethnicities have $70-80 \%$ frequencies of the C825T allele, and in these populations, the CC genotype is rare. ${ }^{30}$ These variations in the $\mathrm{C} 825 \mathrm{~T}$ allele have important metabolic effects, as discussed below.

Weight management. G-protein gene variants have been shown to be directly implicated in weight regulation. ${ }^{23-25}$ The C825T polymorphism of the GNB3 subunit gene allows the prediction of whether weight reduction under sibutramine therapy will be successful. Sibutramine is a centrally acting noradrenaline and serotonin reuptake inhibitor; it enhances satiety and is used extensively to support weight loss. In a reduced-calorie weight-loss intervention study, the CC-genotype obese subjects benefited from sibutramine, whereas the CT-genotype individuals did not. ${ }^{25}$

A similar observation has been made for the GNAS gene, which encodes the G protein Gas ("stimulatory" G protein) mediating the increase in cyclic adenosine monophosphate in many cell types following hormonal stimulation. The GNAS G(-1211)A genotype also influences the subject's response to sibutramine-induced weight-loss intervention. Whereas individuals with the GG genotype can lose weight without the drug and are even at risk for exaggerated heart rate changes without benefiting from the drug, carriers of the A allele benefit from adjunct drug therapy. Several further SNPs occur in the GNAS gene, which together form a relevant haplotype.

The GNA11 G(-659)C genotype in the G protein Ga11 also has a strong influence on the sibutramine intervention; individuals with the CC genotype lose up to $20 \%$ of their original body weight, those with the GC genotype lose $10 \%$, and those with the GG genotype lose barely more than $8 \%$ under drug treatment. As for GNAS G(-1211)A, individuals with the GG genotype are at risk 
for exaggerated changes in heart rate. ${ }^{23}$ Taken together, these results suggest that G-protein-directed genotyping could make sibutramine therapy safe and efficient, as well as making a nutritional intervention generally more powerful.

Many women struggle with post-pregnancy weight retention. Studies of young female subjects of different ethnic backgrounds suggest that GNB3 825T carriers have a greater risk of developing obesity and postpregnancy weight retention. The $825 \mathrm{~T}$ allele of the G-protein $\beta 3$ gene is associated with higher body mass index (BMI) across different ethnicities. Primiparous homozygous carriers of the GNB3 825T allele are at high risk of obesity and post-pregnancy weight retention. ${ }^{24}$ These investigations have been confirmed in white subjects with and without hypertension.

Hypertension and metabolic syndrome. The majority of G-protein studies in Caucasians reveal a positive association between $825 \mathrm{~T}$ allele carrier status in the GNB3 subunit gene and risk of hypertension. This has been demonstrated in particular for large populations genotyped from a German and Belgian study. ${ }^{6}$ There is evidence that $825 \mathrm{~T}$ allele frequency is greater in patients with hypertension and typical features of the metabolic syndrome $e^{6}$; young, lean, normotensive male $825 \mathrm{~T}$ allele carriers already display features of the metabolic syndrome, such as high total cholesterol and uric acid concentration but not yet insulin resistance. Similar metabolic deviations were found in older European and Japanese subjects. In older subjects with hypertension and the TT or TC genotype of GNB3, insulin resistance appears to be more common than in individuals with the CC genotype. Taken together, the cited studies raise the question of whether hypertension associated with the C825T polymorphism may be just one feature of the metabolic syndrome. The $825 \mathrm{~T}$ association with risk of type 2 diabetes mellitus remains to be proved. ${ }^{6}$

Atherosclerosis. A few studies, most of them performed in Caucasian populations, examined the association between the C825T allele in the G-protein $\beta 3$ subunit gene and atherosclerosis, pre-atherosclerotic phenotypes, stroke, and myocardial infarction. Young, white, male 825T allele carriers have greater cardiac stroke volume, greater arterial stiffness, and greater prevalence of radial artery hypertrophy. The last association is independent of age, blood pressure, and BMI. ${ }^{6}$

Digestive health and comfort. Irritable bowel syndrome and functional dyspepsia are well-recognized functional gastrointestinal disorders. These conditions are highly prevalent and often overlap. A clear association was found between the CC genotype of the GNB3 subunit gene and functional dyspepsia; homozygous G-protein B3 825C carriers are associated with unexplained, predominantly upper abdominal symptoms, although no firm conclusion could be drawn with regard to associations with irritable bowel syndrome. ${ }^{26}$

\section{EPIGENETICS}

\section{What is epigenetics?}

As mentioned above, the word "epigenetics" means "above genetics" and generally refers to mechanisms that control gene expression without changing the DNA sequence. Epigenetic changes encompass molecular modifications to DNA and chromatin. ${ }^{12,13}$ The most extensively investigated modifications are DNA methylation and changes to chromatin packaging of DNA by post-translational histone modifications. ${ }^{12,13}$ Other epigenetic mechanisms include regulation by noncoding RNAs, such as microRNAs, and mechanisms that control the higher-level organization of chromatin within the nucleus, which also affects gene expression. ${ }^{31}$ Two of the most comprehensively studied epigenetically regulated phenomena in mammals are $\mathrm{X}$-chromosome inactivation $^{32}$ and genomic imprinting, a genetic mechanism that controls gene expression in a parent of origin-specific manner. ${ }^{16,33}$ Epigenetic regulation is furthermore involved in tissue-specific gene expression and silencing. ${ }^{34}$

Disorders involving dysfunction of imprinted genes are likely to have an epigenetic component. Individuals have two copies, or alleles, of most genes. One is inherited from the mother and one from the father. When both copies of a gene are active, the system exhibits redundancy and hence is less susceptible to dysfunction, but with imprinted genes, one copy is turned off epigenetically. These imprinted genes are susceptibility loci for disease because a single genetic event can alter their normal function. ${ }^{35}$ Epigenetic events can also cause or contribute to diseases if imprinted genes are not completely turned off.

Epigenetic modifications alter gene expression but not gene sequence. Therefore, characterizing the expression profiles of epigenetically controlled genes should reveal epigenetic biomarkers for disease, exposure, intervention, and efficacy. In turn, this should enable early diagnosis of individuals with a propensity for adult-onset disease and could lead to novel therapeutic approaches that could prevent and treat diseases before symptoms develop. This is in contrast with current human disease management, which mainly treats diseases after onset. In particular, modern nutrition focuses on disease prevention and health maintenance, and epigenetics may 
provide the means to understand and achieve these goals. Ultimately, comprehensive knowledge of the human epigenome is required, because the epigenome is not only tissue and stage-of-life dependent, it also varies markedly between individuals and species.

Epigenetics provides a biological format of longterm effects of environmental experiences, metabolic programming, and adaptive development of an organism. ${ }^{31}$ Epigenetic changes occur most commonly during gestation, neonatal development, puberty, and old age. During early embryogenesis, the mammalian genome is "cleansed" of most epigenetic marks, which are progressively re-established during embryonic development. ${ }^{36}$ The epigenome is therefore most vulnerable to environmentally induced alterations during embryogenesis, when DNA synthesis is rapid and the DNA methylation pattern and chromatin structure required for normal development is established. Once established, these epigenetic alterations are passed on to the daughter cells during somatic cell division. Epigenetic marks that are not completely erased during gametogenesis or are not well re-established during embryonic development can affect health not only in the present, but also in future generations. ${ }^{35}$ In addition, epigenetic marks may be transmitted across generations, either directly, by persisting through meiosis, or indirectly, through replication in the next generation of the conditions in which the epigenetic change occurred. ${ }^{36}$ Compelling evidence supports both the developmental origins of health and disease and the underlying epigenetic mechanisms. ${ }^{36}$

There is little doubt that environmentally (e.g., nutritionally) induced changes may significantly affect the ontology of individual organisms. Epigenetic research involving monozygotic twins has provided evidence for this hypothesis. ${ }^{37}$ Such studies typically provide correlations between phenotypic differences and differences in DNA-methylation patterns. Little is known about genes that are particularly prone to undergo environmentally influenced epigenetic changes and about the role of such changes in the generation of specific phenotypes. Consequently, analysis of environmentally or nutritionally induced epigenetic changes should primarily focus on the few "metastable" epialleles that have been characterized to date, ${ }^{31}$ on imprinted genes, and on genes known to be associated with a particular phenotype, such as obesity. Regarding the latter gene type, experiments should concentrate on the genes carrying CpG islands, because these are frequently methylated.

Environmental influences can alter gene expression and change phenotype, in part by modifying the epigenome. If these environmentally induced epigenetic modifications occur at crucial stages of life, they can potentially change behavior, disease susceptibility, and survival. Today's mechanistic evidence of environmental epige- netic imprinting or programming, by nutritional or other means, mainly derives from animal models, but human epidemiological studies also point increasingly toward associations between environmental effects - especially prenatal and early postnatal - and long-term epigenetic modifications manifesting in health and disease phenotypes. ${ }^{38,39}$ Results of animal and human studies support the hypothesis that there is a fetal basis or developmental origin of adult-onset disease; evolution of developmental plasticity, which enables an organism to adapt to environmental signals during early life, can also increase the risk of chronic diseases when there is a mismatch between the early perceived environment and the one encountered in adulthood. Developmental plasticity manifests when environmental exposure produces a broad range of adult phenotypes from a single genotype by epigenetically altering gene expression. ${ }^{40,41}$

\section{Early nutrition, late-life consequences, and epigenetics}

The fetal environment can influence an individual's likelihood of developing chronic disorders during adulthood. Early evidence of this appeared in research showing higher rates of cardiovascular disease in historical cohorts that had experienced high infant mortality. ${ }^{36}$ Further studies revealed an inverse relationship between birth weight and the development of hypertension, cardiovascular morbidity, insulin resistance, type 2 diabetes mellitus, hyperlipidemia, and obesity. ${ }^{36}$ It was therefore hypothesized that fetal metabolic programming under nutritionally adverse circumstances (i.e., those under which fetal growth is restricted in order to ensure brain development) may result in greater risk of chronic disorders later in life, ${ }^{42}$ although other data (e.g., from survivors of the Dutch "hunger winter" of 1944/1945) indicate that individuals exposed to adverse conditions in utero may subsequently exhibit adverse effects even if they do not have a low birth weight. ${ }^{38}$ This observation is consistent with the complex relationship between birth weight and risk of cardiovascular disease ${ }^{43}$ and with the observation that metabolic dysfunction correlates more strongly with neonatal adiposity and maternal nutrition than with birth weight. ${ }^{39,44}$

Other studies have focused on the role of excess nutrition during pregnancy and rapid weight gain in infants ${ }^{40}$ the risk of which is greater after impaired fetal growth. Also, children who are exposed to hyperglycemia in utero or whose mothers are obese are at greater risk of developing metabolic disorders, especially type 2 diabetes mellitus. ${ }^{41}$ Most studies performed so far, however, have focused on the pathways through which undernutrition during development translates into subsequent metabolic disease, despite the fact that fetal nutrition depends not 
on maternal food intake but on maternal metabolism, cardiovascular function, and, particularly, placental function. ${ }^{36}$

Developing organisms seem to be particularly susceptible to epigenetic changes. The periconceptional period is particularly important, as shown by the sensitivity to suboptimal nutrition that occurs during this developmental stage ${ }^{45,46}$ in which widespread reprogramming of the epigenome occurs. ${ }^{47}$ Nutritional constraints later in pregnancy ${ }^{38,48}$ and/or postnatal overnutrition that leads to rapid growth, ${ }^{40,48}$ as well as maternal-fetal overnutrition, ${ }^{49}$ can also cause metabolic dysfunction later in life. For each of these scenarios, relevant epigenetic changes have been reported. ${ }^{50-52}$

The importance of the periconceptional period, during which suboptimal nutrition can have long-lasting effects without causing any change in birth weight, ${ }^{38,46}$ underscores the importance of healthy nutrition during the prepregnancy period. During this time, nutrition may frequently be unbalanced, even in women in highincome countries. ${ }^{53}$ The related finding that the balance of micronutrients involved in one-carbon metabolism during pregnancy affects the subsequent metabolic health of the offspring ${ }^{54}$ has implications for the design of nutritional supplementation programs. Research in animal models has demonstrated that nutritional interventions (such as folate supplementation) or endocrinological interventions (such as neonatal leptin administration) can prevent ${ }^{55}$ or reverse ${ }^{52,56}$ the adverse effects of impaired early-life nutrition and the associated epigenetic changes.

Maternal overnutrition may contribute to transgenerational amplification of obesity in humans. ${ }^{57}$ In the Agouti mouse model, dietary supplementation with substrates and cofactors of DNA methylation abrogate such female-line transmission of obesity. ${ }^{58}$ Also, early treatment with a histone deacetylase inhibitor, a drug class for clinical oncological trials, can reverse the phenotypic and epigenetic consequences of intrauterine growth retardation for pancreatic development and adult-onset diabetes mellitus. ${ }^{59}$ Offspring of rats given a low-protein diet during pregnancy have a different hepatic gene expression, gene promoter methylation, and histone acetylation of metabolically relevant receptors: the glucocorticoid receptor and the peroxisome proliferator-activated receptor $\alpha$. Later in life, the offspring develop abnormalities of metabolic control and cardiovascular function. Concurrently supplementing the diet of the pregnant dam with folate, which promotes methyl group provision, prevents these effects. ${ }^{55}$ Studies in pregnant rodents subject to a variety of dietary challenges or to exposure to glucocorticoids show a relatively consistent outcome for the offspring, i.e., abnormalities of insulin secretion and sensitivity, sarcopenia, appetite disturbance, obesity, and endothelial dysfunction. ${ }^{60}$ These features are particularly apparent when the animals are placed on a high-fat diet after weaning. ${ }^{48}$

Primary candidates for genes holding epigenetic memories of early-life experiences are those that are directly associated with energy acquisition, storage, and use. Leptin is thought to be one of the best gene candidates involved in the development of obesity, because it encodes a hormone that regulates energy intake and expenditure. ${ }^{61}$ Epigenetic variants of leptin could possibly explain low plasma concentrations of this fat hormone. The promoter region of leptin is methylated in somatic tissues of humans and mice and displays epigenetic variation. ${ }^{62-64}$ It is speculated that leptin is sensitive to environmental cues and can acquire a thrifty epigenotype. Other promising candidates are genes listed in the human obesity gene map, ${ }^{65}$ imprinted genes, and genes close to or disrupted by transposable elements.

\section{Genes, nutrition, and the brain}

A great deal of research has focused on the respective binary research interfaces of genomics, cognitive science, and nutrition research, but little is known about the intersection of all three disciplines. For example, how does nutrition affect the brain at the whole genome level? And how does an individual's genetic make-up determine their nutritional response with consequences for cognitive performance and for predisposition toward cognitive decline and disease?

A substantial body of knowledge has already been gathered regarding the interface between nutrition and genes; the fields of nutrigenomics (e.g., how the body responds to diet at the genomic scale ${ }^{66}$ and nutrigenetics $^{67}$ (e.g., how individuals are predisposed to respond to food in a certain way and not in another) are rapidly expanding this knowledge. ${ }^{68}$ The nutrigenetic success story of G-protein polymorphisms was discussed in the preceding section.

Competence is also improving in the interface between nutrition and the brain; that is, how diet affects neurodevelopment, ${ }^{69}$ neurodecline, ${ }^{70}$ and cognitive performance. ${ }^{71}$ However, such studies are typically epidemiological, observational, or associative.

Furthermore, knowledge is accumulating regarding the interface of the brain and the genes (e.g., how individuals are predisposed to the development of cognitive $\operatorname{decline}^{72,73}$ and disease $\mathrm{e}^{74}$ and to respond to nutritional intervention aimed at improving neurodevelopment and cognition as well as preventing neurodecline ${ }^{75}$ ). In recent pioneering studies, initial understanding of how epigenetic and genetic mechanisms may influence cognitive function ${ }^{76}$ and neuronal disease has been gained. ${ }^{77}$ Kalu$\mathrm{eff}^{78}$ reviewed the neurobiology of memory and anxiety 
with the ultimate goal of making the leap from genes to behavior; he summarized experimental data from neurogenetics, neurochemistry, behavioral pharmacology, and clinical findings reflecting mechanisms of the interplay between memory and anxiety, including brain neurochemistry and circuitry, pharmacology, neuroplasticity, genetics, and interactions between genes and environment. ${ }^{78}$ Burmeister et al. ${ }^{79}$ recently updated the science community on progress and controversy in psychiatric genetics; although several psychiatric diseases such as bipolar disorder, schizophrenia, and autism are highly heritable, identifying their genetic basis and replicating the findings are challenging. Nevertheless, the incorporation of intermediate traits (endophenotypes) and environmental factors into genetic analyses and the identification of rare inherited variants and novel structural mutations have advanced the field. The same is expected from larger sample sizes and meta-analyses of such studies and from paying more attention to unique families and rare variants. ${ }^{80}$

The Papassotiropoulos group has shed more light on the genetic basis of cognitive performance and decline; as a methodological recommendation, they suggest identifying the genetic basis for complex disorders using pooling-based genome-wide SNP association studies as a low-cost alternative to individually genotyping thousands of samples on high-density SNP microarrays. ${ }^{81}$ They also reviewed the application of genetics, transcriptomics, and proteomics to Alzheimer's disease (AD),${ }^{81}$ discussing, for example, rare mutations of APP and presenilin 1/2 and their importance for amyloid metabolism ${ }^{81}$ and apolipoprotein $\mathrm{E}$ (APOE) as an important susceptibility gene for late-onset $\mathrm{AD}{ }^{82}$ The same group, together with others, has also published a number of research articles on associations between genes and performance, with a focus on memory; except for a genome survey of human shortterm memory, ${ }^{83}$ memory performance was concretely associated with genetic variability in a gene locus encoding the brain protein $\mathrm{KIBRA}^{84}$; APOE, the major genetic $\mathrm{AD}$ risk factor ${ }^{85}$ (with the APOE $\varepsilon 4$ allele associated with better episodic memory than the APOE $\varepsilon 2$ and $\varepsilon 3$ alleles in young, healthy persons); a gene cluster encoding proteins of a signalling cascade encompassing the $\mathrm{N}$-methyl$\mathrm{D}$-aspartic acid and metabotropic glutamate receptors, adenylyl cyclase, Ca $2+/$ calmodulin-dependent protein kinase II, protein kinase $(\mathrm{pK}) \mathrm{A}$, and $\mathrm{pKC}^{86}$; and the calmodulin-binding transcription activator 1 gene $^{87}$ (which influences episodic memory). In an extension of the genetic determination of memory, de Quervain et al. ${ }^{88}$ assessed emotional memory and identified an association with a deletion variant of the $\alpha 2 b$-adrenoceptor, which is related to differential amygdala activation during encoding of emotional memories. ${ }^{89}$ Payton et al. ${ }^{90}$ assessed the influence of serotonin transporter gene polymorphisms on cognitive decline and cognitive abilities in older adults without dementia, focusing on two functional SNPs within the SLC6A4 and VNTR2 genes. They found subjects homozygous for the VNTR2 12 allele to decline more rapidly on all cognitive tests, with significance reached for tests of fluid intelligence, semantic memory, and general cognitive ability. VNTR2 is only the second gene reported to regulate the rate of cognitive decline in individuals without dementia, and it may become a target for the treatment of cognitive impairment in older adults. $^{90}$

Although these pioneering studies point toward genetic susceptibility loci, replication of such findings in genome-wide association studies (GWAS) has been challenging, as with most complex disorders and phenotypes; Need et al. ${ }^{11}$ performed a GWAS of 11 cognitive phenotypes from the Cambridge Neuropsychological Test Automated Battery. They showed these measures to be heritable by comparing the correlation in 100 monozygotic and 100 dizygotic twin pairs; the full battery was tested in approximately 750 subjects, and a further 500 individuals were investigated for spatial and verbal recognition memory to search for smaller genetic effects. Unfortunately, the authors were not able to establish any significant genome-wide associations with SNPs or copy number variants, nor could they replicate any polymorphism previously associated with cognition. The group also investigated - as a separate set - SNPs in genomic loci that had been shown to harbor rare variants associated with neuropsychiatric disorders. Only NRXN1 showed evidence of significant association with cognition. Need et al. ${ }^{91}$ concluded that common genetic variation has little influence on cognition in healthy subjects and that cognitive measures do not represent a moretractable genetic trait than clinical endpoints.

In summary, we are learning how gene variants may influence cognitive performance on the one hand and the outcome of nutritional interventions on the other hand. In contrast, the intersection of genomics, cognitive science, and nutrition research, that is, how nutrition affects the brain genome-wide and how (epi)genetics may determine an individual's nutritional response with consequences for cognitive performance and decline, remains largely uncharted terrain. This is especially true for human studies, and one reason is the difficult sampling; genome-wide analyses of mechanisms of neuronal decline in the brain are limited to animal studies or to postmortem brain biopsies of affected subjects. In the search for early biomarkers, cerebrospinal fluid (the liquid surrounding the brain) may offer an alternative, ${ }^{92}$ and cerebrospinal fluid studies have identified candidate protein biomarkers for brain diseases. ${ }^{93}$ GWAS have revealed (candidate) genetic risk loci for diseases including $\mathrm{AD}$ and Parkinson's disease. ${ }^{74}$ To our knowledge 
(epi)genetic predisposition to cognition-promoting nutritional interventions has not been investigated.

\section{CONCLUSION}

Research in the field of genetics has been performed to date in two formats: hypothesis-driven candidate gene approaches and GWAS. The first category of studies contains examples of how genetic predisposition, for example, in the form of SNPs (which are the most prominent source of interindividual genetic variability) or copy number polymorphisms, determines or strongly influences the response to a given environmental (e.g., nutritional) stimulus.

GWAS have identified a number of (candidate) risk loci for the development or (early) onset of certain diseases, including common and complex ones. However, the power of these risk loci to predict health trajectories has, so far, been small, even if several loci have meanwhile been replicated and taken together in a combined score. In contrast, combining these genetic scores with environmental scores ${ }^{94}$ appears to be a more powerful tool for predicting health outcomes and disease risk, and eventually feeds into lifestyle advice. Hence, it may become possible in the not-too-distant future to routinely genetically stratify cohorts in clinical (nutritional or pharmaceutical) intervention studies, discern responders from nonresponders, thereby improving study readout, and to combine genetic scores with lifestyle scores to obtain an overall health prospect and disease risk assessment.

Epigenetics may provide mechanisms by which metabolic programming can be understood and even influenced. Together with genetics and genomics, it forms a set of scientific building blocks for further developing evidence-based and mechanism-rooted personalized nutrition and treatment. Epigenetic changes are interpreted as chemical switches that can turn on and off the expression of genes in response to environmental cues. Defective genes are damaged for life; however, there is emerging evidence from animal models that genes can be demethylated or remethylated, which may open the opportunity for reprogramming, possibly using nutritional means. Epigenetic changes occur most commonly during gestation, neonatal development, puberty, and old age. The epigenome is most vulnerable to environmentally induced alterations during embryogenesis. The perinatal period appears to be especially prone to environmental effects that have long-term consequences for health outcomes and disease risk. Some epigenetic changes can increase disease risk if they lead to deregulation of genes or if there is a mismatch between the environment that is present during development and the environment encountered in adulthood. Most of the current evidence for epigenetic programming stems from cancer research and derives from animal models. Although discussions have taken place regarding whether or not trans-generational inheritance of environmentally induced epigenetic changes is of significance in mammals, there is little doubt that such environmentally (nutritionally) induced changes may significantly affect the ontology of individual organisms.

In our opinion, a holistic approach of genomics (including transcriptomics, proteomics, and metabolomics), genetics, and epigenetics is required to understand human variability and to develop biomarkers for response and efficacy, individual disposition, and programming of an organism, respectively. This concept applies, in our view, to nutrition just as much as it does to pharmaceutical research.

One of the reasons the understanding of environmental modeling of a genome is only beginning may be that the aforementioned integration of genomics (expression), genetics (predisposition), and epigenetics (programming or imprinting) is just emerging and that the tools for genome-wide analyses are still maturing. In the fields of infant nutrition, diabetes, obesity, and the metabolic syndrome, the term "metabolic programming" has been coined to give a name to the observation that environmental experiences early in life may be "genomically" remembered and give rise to health outcomes manifesting later in life. Epigenetics emerges as an important mechanism underlying this phenomenon.

The phenomenon of childhood exposure resulting in adult behavior is not new; a child who has already watched many science fiction videos at an early age may be difficult to convince to read a book or to explore nature later on. This basic educational experience may be called an aspect of "cognitive programming." With the mechanisms responsible for this remaining largely elusive, and with integrated genomics and (epi)genetics bearing the potential to shed more light on it, it is the study design and the difficult sampling that render such investigations in humans extremely challenging. The cognitive sciences continue to thrive towards the ultimate goal of understanding how the brain functions. However, while humans are developing a systems-level understanding of biological entities less complex than humans themselves, they are and will probably remain far away from such systems-level understanding of their own species.

\section{Acknowledgments}

Declaration of interest. This work was commissioned by the Nutrition and Mental Performance Task Force of the European branch of the International Life Sciences Institute (ILSI Europe). Industry members of this task force are Abbott Nutrition, Barilla G. \& R. Fratelli, Coca-Cola Europe, Danone, Dr Willmar Schwabe, DSM, 
FrieslandCampina, Kellogg Europe, Kraft Foods, Martek Biosciences Corporation, Naturex, Nestlé, PepsiCo International, Pfizer, Roquette, Soremartec - Ferrero Group, Südzucker/BENEO Group, Unilever. For further information about ILSI Europe, please call +32-2-771-00-14 or email: info@ilsieurope.be. The opinions expressed herein are those of the authors and do not necessarily represent the views of ILSI Europe. Dr M. Kussmann is an employee of Nestlé. Dr W. Siffert is a consultant to Eurofins Medigenomix Inc. Dr L. Krause has no conflict of interest to declare. The coordinator for this supplement was Ms Agnes Meheust, ILSI Europe.

\section{REFERENCES}

1. Lander ES, Linton $L M$, Birren $B$, et al. Initial sequencing and analysis of the human genome [Review]. Nature. 2001;409:860-921.

2. Venter JC, Adams MD, Myers EW, et al. The sequence of the human genome [Review]. Science. 2001;291:1304-1351.

3. Kussmann M, Rezzi S, Daniel H. Profiling techniques in nutrition and health research. Curr Opin Biotechnol. 2008;19:8399.

4. Kussmann M, Raymond F, Affolter M. OMICS-driven biomarker discovery in nutrition and health. J Biotechnol. 2006;124:758-787.

5. Manolio TA. Cohort studies and the genetics of complex disease. Nat Genet. 2009;41:5-6.

6. Siffert W. G protein polymorphisms in hypertension, atherosclerosis, and diabetes. Annu Rev Med. 2005;56:1728.

7. Lyssenko V, Jonsson A, Almgren P, et al. Clinical risk factors, DNA variants, and the development of type 2 diabetes. $\mathrm{N}$ Engl J Med. 2008;359:2220-2232.

8. Meigs JB, Shrader P, Sullivan LM, et al. Genotype score in addition to common risk factors for prediction of type 2 diabetes. N Engl J Med. 2008;359:2208-2219.

9. Maher B. Personal genomes: the case of the missing heritability. Nature. 2008;456:18-21.

10. Zeggini $\mathrm{E}$, Weedon $\mathrm{MN}$, Lindgren $\mathrm{CM}$, et al. Replication of genome-wide association signals in UK samples reveals risk loci for type 2 diabetes. Science. 2007;316:1336-1341.

11. Blow N. Genomics: the personal side of genomics. Nature. 2007;449:627-630.

12. Klose RJ, Bird AP. Genomic DNA methylation: the mark and its mediators. Trends Biochem Sci. 2006;31:89-97.

13. Talbert PB, Henikoff S. Spreading of silent chromatin: inaction at a distance. Nat Rev Genet. 2006;7:793-803.

14. Briggs SD, Xiao T, Sun ZW, et al. Gene silencing: trans-histone regulatory pathway in chromatin. Nature. 2002;418:498.

15. Fire A, Xu S, Montgomery MK, Kostas SA, Driver SE, Mello CC. Potent and specific genetic interference by double-stranded RNA in Caenorhabditis elegans. Nature. 1998;391:806-811.

16. Reik W, Walter J. Genomic imprinting: parental influence on the genome. Nat Rev Genet. 2001;2:21-32.

17. Strahl $B D$, Allis CD. The language of covalent histone modifications. Nature. 2000;403:41-45.

18. Zhao XJ, Li C, Paez JG, et al. An integrated view of copy number and allelic alterations in the cancer genome using single nucleotide polymorphism arrays. Cancer Res. 2004;64:3060-3071.
19. Nelson MR, Marnellos G, Kammerer S, et al. Large-scale validation of single nucleotide polymorphisms in gene regions. Genome Res. 2004;14:1664-1668.

20. Bourne HR. How receptors talk to trimeric G proteins. Curr Opin Cell Biol. 1997;9:134-142.

21. Downes GB, Gautam N. The G protein subunit gene families. Genomics. 1999;62:544-552.

22. Gautam N, Downes GB, Yan K, Kisselev O. The G-protein betagamma complex. Cell Signal. 1998;10:447-455.

23. Frey $\mathrm{UH}$, Hauner $\mathrm{H}$, Jockel $\mathrm{KH}$, Manthey I, Brockmeyer $\mathrm{N}$, Siffert W. A novel promoter polymorphism in the human gene GNAS affects binding of transcription factor upstream stimulatory factor 1, Galphas protein expression and body weight regulation. Pharmacogenet Genomics. 2008;18:141-151.

24. Gutersohn A, Naber C, Muller N, Erbel R, Siffert W. G protein beta3 subunit 825 TT genotype and post-pregnancy weight retention. Lancet. 2000;355:1240-1241.

25. Hauner H, Meier M, Jockel KH, Frey UH, Siffert W. Prediction of successful weight reduction under sibutramine therapy through genotyping of the G-protein beta3 subunit gene (GNB3) C825T polymorphism. Pharmacogenetics. 2003; 13:453-459.

26. Holtmann G, Siffert W, Haag S, et al. G-protein beta 3 subunit 825 CC genotype is associated with unexplained (functional) dyspepsia. Gastroenterology. 2004;126:971-979.

27. Mitchell A, Rushentsova U, Siffert W, Philipp T, Wenzel RR. The angiotensin II receptor antagonist valsartan inhibits endothelin 1-induced vasoconstriction in the skin microcirculation in humans in vivo: influence of the G-protein beta3 subunit (GNB3) C825T polymorphism. Clin Pharmacol Ther. 2006;79:274-281.

28. Nurnberger J, Dammer S, Mitchell A, et al. Effect of the C825T polymorphism of the $G$ protein beta 3 subunit on the systolic blood pressure-lowering effect of clonidine in young, healthy male subjects. Clin Pharmacol Ther. 2003;74:53-60.

29. Wenzel RR, Siffert W, Bruck H, Philipp T, Schafers RF. Enhanced vasoconstriction to endothelin-1, angiotensin II and noradrenaline in carriers of the GNB3 $825 \mathrm{~T}$ allele in the skin microcirculation. Pharmacogenetics. 2002;12:489495.

30. Siffert W, Forster $\mathrm{P}$, Jockel $\mathrm{KH}$, et al. Worldwide ethnic distribution of the $G$ protein beta3 subunit $825 T$ allele and its association with obesity in Caucasian, Chinese, and Black African individuals. J Am Soc Nephrol. 1999;10:1921-1930.

31. Jirtle RL, Skinner MK. Environmental epigenomics and disease susceptibility. Nat Rev Genet. 2007;8:253-262.

32. Huynh KD, Lee JT. X-chromosome inactivation: a hypothesis linking ontogeny and phylogeny. Nat Rev Genet. 2005;6:410 418.

33. Falls JG, Pulford DJ, Wylie AA, Jirtle RL. Genomic imprinting: implications for human disease. Am J Pathol. 1999;154:635647.

34. Slotkin RK, Martienssen R. Transposable elements and the epigenetic regulation of the genome. Nat Rev Genet. 2007;8:272-285.

35. Jirtle RL. Randy L. Jirtle, PhD: epigenetics a window on gene dysregulation, disease. Interview by Bridget M. Kuehn. JAMA. 2008;299:1249-1250.

36. Gluckman PD, Hanson MA, Buklijas T, Low FM, Beedle AS. Epigenetic mechanisms that underpin metabolic and cardiovascular diseases. Nat Rev Endocrinol. 2009;5:401-408.

37. Fraga MF, Ballestar E, Paz MF, et al. Epigenetic differences arise during the lifetime of monozygotic twins. Proc Natl Acad Sci U S A. 2005;102:10604-10609. 
38. Painter RC, Roseboom TJ, Bleker OP. Prenatal exposure to the Dutch famine and disease in later life: an overview. Reprod Toxicol. 2005;20:345-352.

39. Yajnik CS. Early life origins of insulin resistance and type 2 diabetes in India and other Asian countries. J Nutr. 2004;134:205-210.

40. Singhal A. Early nutrition and long-term cardiovascular health. Nutr Rev. 2006;64:S44-S49.

41. Boney CM, Verma A, Tucker R, Vohr BR. Metabolic syndrome in childhood: association with birth weight, maternal obesity, and gestational diabetes mellitus. Pediatrics. 2005;115:e290e296.

42. Hales CN, Barker DJ. Type 2 (non-insulin-dependent) diabetes mellitus: the thrifty phenotype hypothesis. Diabetologia. 1992;35:595-601.

43. Osmond C, Barker DJ, Winter PD, Fall CH, Simmonds SJ. Early growth and death from cardiovascular disease in women. BMJ. 1993;307:1519-1524.

44. Kuzawa CW, Adair LS. Lipid profiles in adolescent Filipinos: relation to birth weight and maternal energy status during pregnancy. Am J Clin Nutr. 2003;77:960-966.

45. Sinclair KD, Allegrucci C, Singh R, et al. DNA methylation, insulin resistance, and blood pressure in offspring determined by maternal periconceptional B vitamin and methionine status. Proc Natl Acad Sci U S A. 2007;104:1935119356.

46. Heijmans BT, Tobi EW, Stein AD, et al. Persistent epigenetic differences associated with prenatal exposure to famine in humans. Proc Natl Acad Sci U S A. 2008;105:17046-17049.

47. Nafee TM, Farrell WE, Carroll WD, Fryer AA, Ismail KM. Epigenetic control of fetal gene expression. BJOG. 2008;115:158168.

48. Vickers MH, Breier BH, Cutfield WS, Hofman PL, Gluckman PD. Fetal origins of hyperphagia, obesity, and hypertension and postnatal amplification by hypercaloric nutrition. Am J Physiol Endocrinol Metab. 2000;279:E83-E87.

49. Schaefer-Graf UM, Pawliczak J, Passow D, et al. Birth weight and parental BMI predict overweight in children from mothers with gestational diabetes. Diabetes Care. 2005;28:1745-1750.

50. Aagaard-Tillery KM, Grove K, Bishop J, et al. Developmental origins of disease and determinants of chromatin structure: maternal diet modifies the primate fetal epigenome. J Mol Endocrinol. 2008;41:91-102.

51. Waterland RA, Lin JR, Smith CA, Jirtle RL. Post-weaning diet affects genomic imprinting at the insulin-like growth factor 2 (Igf2) locus. Hum Mol Genet. 2006;15:705-716.

52. Gluckman PD, Lillycrop KA, Vickers $M H$, et al. Metabolic plasticity during mammalian development is directionally dependent on early nutritional status. Proc Natl Acad Sci U S A. 2007;104:12796-12800.

53. Robinson SM, Crozier SR, Borland SE, Hammond J, Barker DJ, Inskip HM. Impact of educational attainment on the quality of young women's diets. Eur J Clin Nutr. 2004;58:11741180.

54. Yajnik CS, Deshpande SS, Jackson AA, et al. Vitamin B12 and folate concentrations during pregnancy and insulin resistance in the offspring: the Pune Maternal Nutrition Study. Diabetologia. 2008;51:29-38.

55. Lillycrop KA, Phillips ES, Jackson AA, Hanson MA, Burdge GC. Dietary protein restriction of pregnant rats induces and folic acid supplementation prevents epigenetic modification of hepatic gene expression in the offspring. J Nutr. 2005;135:1382-1386.
56. Vickers MH, Gluckman PD, Coveny AH, et al. Neonatal leptin treatment reverses developmental programming. Endocrinology. 2005;146:4211-4216.

57. Lawlor DA, Smith GD, O'Callaghan M, et al. Epidemiologic evidence for the fetal overnutrition hypothesis: findings from the mater-university study of pregnancy and its outcomes. Am J Epidemiol. 2007;165:418-424.

58. Waterland RA, Travisano M, Tahiliani KG, Rached MT, Mirza S. Methyl donor supplementation prevents transgenerational amplification of obesity. Int J Obes (Lond). 2008;32:13731379.

59. Park JH, Stoffers DA, Nicholls RD, Simmons RA. Development of type 2 diabetes following intrauterine growth retardation in rats is associated with progressive epigenetic silencing of Pdx1. J Clin Invest. 2008;118:2316-2324.

60. McMillen IC, Robinson JS. Developmental origins of the metabolic syndrome: prediction, plasticity, and programming. Physiol Rev. 2005;85:571-633.

61. Friedman JM, Halaas JL. Leptin and the regulation of body weight in mammals. Nature. 1998;395:763-770.

62. Yokomori N, Tawata M, Onaya T. DNA demethylation modulates mouse leptin promoter activity during the differentiation of 3T3-L1 cells. Diabetologia. 2002;45:140-148.

63. Melzner I, Scott V, Dorsch K, et al. Leptin gene expression in human preadipocytes is switched on by maturation-induced demethylation of distinct CpGs in its proximal promoter. J Biol Chem. 2002;277:45420-45427.

64. Antequera F, Boyes J, Bird A. High levels of de novo methylation and altered chromatin structure at $\mathrm{CpG}$ islands in cell lines. Cell. 1990;62:503-514.

65. Rankinen T, Zuberi A, Chagnon YC, et al. The human obesity gene map: the 2005 update. Obesity (Silver Spring). 2006;14:529-644.

66. Ordovas JM, Corella D. Nutritional genomics. Annu Rev Genomics Hum Genet. 2004;5:71-118.

67. Ordovas JM, Mooser V. Nutrigenomics and nutrigenetics. Curr Opin Lipidol. 2004;15:101-108.

68. Kaput J. Nutrigenomics research for personalized nutrition and medicine. Curr Opin Biotechnol. 2008;19:110-120.

69. Pearce MS, Deary IJ, Young AH, Parker L. Growth in early life and childhood IQ at age 11 years: the Newcastle Thousand Families Study. Int J Epidemiol. 2005;34:673-677.

70. Feart C, Samieri C, Barberger-Gateau P. Mediterranean diet and cognitive function in older adults. Curr Opin Clin Nutr Metab Care. 2009.

71. le Coutre J, Schmitt JA. Food ingredients and cognitive performance. Curr Opin Clin Nutr Metab Care. 2008;11:706-710.

72. Nokelainen P, Flint J. Genetic effects on human cognition: lessons from the study of mental retardation syndromes. J Neurol Neurosurg Psychiatry. 2002;72:287-296.

73. Francks C, Fisher SE, Marlow AJ, et al. Familial and genetic effects on motor coordination, laterality, and reading-related cognition. Am J Psychiatry. 2003;160:1970-1977.

74. Latourelle JC, Pankratz N, Dumitriu A, et al. Genomewide association study for onset age in Parkinson disease. BMC Med Genet. 2009;10:98.

75. Levi RS, Sanderson IR. Dietary regulation of gene expression. Curr Opin Gastroenterol. 2004;20:139-142.

76. Pinsonneault JK, Papp AC, Sadee W. Allelic mRNA expression of $X$-linked monoamine oxidase a (MAOA) in human brain dissection of epigenetic and genetic factors. Hum Mol Genet. 2006;15:2636-2649.

77. Hogart A, Nagarajan RP, Patzel KA, Yasui DH, Lasalle JM. 15q11-13 GABAA receptor genes are normally biallelically 
expressed in brain yet are subject to epigenetic dysregulation in autism-spectrum disorders. Hum Mol Genet. 2007;16:691703.

78. Kalueff AV. Neurobiology of memory and anxiety: from genes to behavior. Neural Plast. 2007;2007:78171.

79. Burmeister M, Mclnnis MG, Zollner S. Psychiatric genetics: progress amid controversy. Nat Rev Genet. 2008;9:527-540.

80. Pearson JV, Huentelman MJ, Halperin RF, et al. Identification of the genetic basis for complex disorders by use of poolingbased genomewide single-nucleotide-polymorphism association studies. Am J Hum Genet. 2007;80:126-139.

81. Papassotiropoulos A, Fountoulakis M, Dunckley $T$, Stephan DA, Reiman EM. Genetics, transcriptomics, and proteomics of Alzheimer's disease. J Clin Psychiatry. 2006; 67(4):652-670.

82. Coon KD, Myers AJ, Craig DW, et al. A high-density wholegenome association study reveals that APOE is the major susceptibility gene for sporadic late-onset Alzheimer's disease. J Clin Psychiatry. 2007;68:613-618.

83. Papassotiropoulos A, Henke K, Stefanova E, et al. A genomewide survey of human short-term memory. Mol Psychiatry. Advance online publication, 29 December 2009; doi: 10.1038/mp.2009.133.

84. Papassotiropoulos A, Stephan DA, Huentelman MJ, et al. Common Kibra alleles are associated with human memory performance. Science. 2006;314:475-478.

85. Mondadori CR, de Quervain DJ, Buchmann A, et al. Better memory and neural efficiency in young apolipoprotein $E$ epsilon4 carriers. Cereb Cortex. 2007;17:1934-1947.

86. de Quervain DJ, Papassotiropoulos A. Identification of a genetic cluster influencing memory performance and hippocampal activity in humans. Proc Natl Acad Sci U S A. 2006;103:4270-4274.
87. Huentelman MJ, Papassotiropoulos A, Craig DW, et al. Calmodulin-binding transcription activator 1 (CAMTA1) alleles predispose human episodic memory performance. Hum Mol Genet. 2007;16:1469-1477.

88. de Quervain DJ, Kolassa IT, Ertl V, et al. A deletion variant of the alpha2b-adrenoceptor is related to emotional memory in Europeans and Africans. Nat Neurosci. 2007;10:1137-1139.

89. Rasch B, Spalek K, Buholzer S, et al. A genetic variation of the noradrenergic system is related to differential amygdala activation during encoding of emotional memories. Proc Natl Acad Sci U S A. 2009;106:19191-19196.

90. Payton A, Gibbons L, Davidson Y, et al. Influence of serotonin transporter gene polymorphisms on cognitive decline and cognitive abilities in a nondemented elderly population. Mol Psychiatry. 2005;10:1133-1139.

91. Need AC, Attix DK, McEvoy JM, et al. A genome-wide study of common SNPs and CNVs in cognitive performance in the CANTAB. Hum Mol Genet. 2009;18:4650-4661.

92. Zappaterra MD, Lisgo SN, Lindsay S, Gygi SP, Walsh CA, Ballif BA. A comparative proteomic analysis of human and rat embryonic cerebrospinal fluid. J-Proteome-Res. 2007;6: 3537-3548.

93. Khwaja FW, Nolen JDL, Mendrinos SE, et al. Proteomic analysis of cerebrospinal fluid discriminates malignant and nonmalignant disease of the central nervous system and identifies specific protein markers. Proteomics Dec. 2006;6:6277-6287.

94. Firmann M, Mayor V, Vidal PM, et al. The CoLaus study: a population-based study to investigate the epidemiology and genetic determinants of cardiovascular risk factors and metabolic syndrome. BMC Cardiovasc Disord. 2008;8:6. 